\title{
NO-COST LANDSAT DATA REDEFINES STUDENT RESEARCH PROJECTS IN APPLIED REMOTE SENSING CLASSES AT UW
}

\author{
Ramesh Sivanpillai \\ Wyoming GIS Center, University of Wyoming, Laramie, WY 82071, USA - sivan@uwyo.edu
}

KEY WORDS: Undergraduate Curriculum, Workforce Development, Research Projects, WyomingView

\begin{abstract}
:
Students enrolled in an applied remote sensing class at University of Wyoming are required to complete a term research project. They have to apply the concepts learned throughout the semester to address a real-world problem in a natural resource management topic that uses remotely sensed imagery data. Prior to the availability of no-cost Landsat data, students in this class had to restrict the scope of their projects to images available in the smaller archives maintained by academic and research institutions. Since the US Geological Survey (USGS) made the entire Landsat archive available at no-cost, opportunities have increased for students to use those data in class projects. Now, students can download as many Landsat images as is needed to address the scope of their project. Using examples from previous years, this paper describes how no-cost Landsat imagery has allowed students enrolled in an applied remote sensing class to add depth and breadth to their projects.
\end{abstract}

\section{INTRODUCTION}

Research projects that are a part of most college remote sensing courses require students to apply the concepts they have learned in lectures and labs to address real world problems. If these projects are conducted in areas that are familiar to the students, they will be able to better relate the image information to conditions on the ground and enhance their understanding (Sivanpillai and Driese, 2008). In order to complete such projects, students need to have access to remotely sensed data acquired at the appropriate time, i.e., year, season, or month.

Historically, the cost associated with obtaining imagery for classroom projects was the primary limiting factor. In many US institutions, instructors would provide sample images obtained from data or software vendors. At certain institutions faculty used imagery purchased through other research grants in their classrooms. These images were acquired for some random location in the world i.e., a lake and its adjoining area in the south-eastern US or a random landscape in Africa. Students enrolled in remote sensing courses in different years or semesters would process the same set of images. In research active institutions, faculty would hire undergraduate students to complete one or more research tasks, and those students would gain additional research experience. However, other students, especially those enrolled in teaching institutions were not able to gain this research experience during their academic careers.

The Landsat satellite program (http://landsat.usgs.gov) has been collecting Earth Observation (EO) data since 1972. Imagery data acquired by Landsat satellites $1-5,7$ and 8 constitute the longest and continuous collection of moderate resolution EO data (Loomis et al. 2015). The spatial and spectral resolutions of Thematic Mapper (TM), Enhanced Thematic Mapper (ETM+), and Operational Land Imaginer (OLI) sensors on board Landsat 5, 7 and 8 are well suited for monitoring changes caused by natural and anthropogenic factors on the surface of the Earth. The cost associated with purchasing a Landsat image or scene $(\sim 180 \times 180 \mathrm{~km})$ was prohibitive for classroom teaching and term project research activities.
Under those conditions, students had to define the scope of their term projects to match the characteristics of the imagery data they could access. For example, a student interested in studying the effect of drought on vegetation growth might not have access to images acquired during those years. Similarly, another student interested in mapping land cover changes in a region, might not have access to images acquired before and after certain policies were implemented. Hence the scope of the projects had to be modified to match the already available data.

The AmericaView (AV) program established in the late 1990s allowed users to access free Landsat imagery from the archives of its member states (Landenberger et al. 2011). Also, users could also purchase Landsat 5 and 7 images or scenes for US\$540 and US\$600 respectively that were no in the archive. However this program was focused primarily on users in the United States. The Global Land Cover Facility (GLCF) operated by University of Maryland (USA) since 1997 also provided several Landsat images and other remotely sensed data acquired for different parts of the world (Lindsay et al., 1999). However, the GLCF archive did not include all Landsat scenes and all the newly acquired images were not uploaded to it. Nevertheless, remotely sensed data contained in the GLCF archive gave students and instructors and opportunity to obtain data from different areas of the world.

In 2008, the USGS opened the entire Landsat collection to users worldwide (Zhu, 2017). A user can download any number or volume of Landsat data for any location in the world (Wulder et al. 2012). This created an unprecedented opportunity for teachers and students enrolled in remote sensing courses. Teachers and students can download images acquired in certain years, seasons or months. As long as they are not covered by clouds and cloud shadows, these images could be used in teaching and term research projects. The 30 meter spatial resolution of Landsat 5, 7 and 8 data also might not be suitable for mapping land cover or tracking changes in highly fragmented landscapes. Nevertheless, studies have demonstrated the utility of these data for mapping urban growth and land conversion throughout the world. Studies have used the spectral information collected by Landsat satellites 5, 7 and 8 to derive secondary information, i.e. spectral indices, which 
are valuable to monitoring or tracking changes in crop growth (Rufin et al., 2019), forest (Hansen et al., 2013; Hughes et al., 2017), and water quantity and quality (Arvor et al., 2018).

This paper describes how no-cost Landsat data has transformed undergraduate student research projects in an applied remote sensing course at the University of Wyoming. Section 2 provides background information about this course, Section 3 describes the changes in the projects completed by these students with Landsat data, and Section 4 includes suggestions and recommendations for the future.

\section{COURSE BACKGROUND}

The University of Wyoming (UW) offers an applied remote sensing course every fall semester. This course is intended for upper level ( $3^{\text {rd }}$ and $4^{\text {th }}$ year) undergraduate students majoring in Rangeland Ecology \& Watershed Management, Agroecology, and Plant Sciences. This course has been continuously taught since 2005 in a lecture and laboratory format and has attracted students from other degree programs such as Geography.

UW junior ( $3^{\text {rd }}$ year) and senior $\left(4^{\text {th }}\right.$ year) students from the College of Agriculture \& Natural Resources as well as the College of Arts \& Sciences have registered for this class. The number of students in this class has varied between 14 and 38 (average of 27). Majority of the students who have completed this course are from small, rural communities in Wyoming. Often students were from families with a farming or ranching background or have gained experience from working on farms or ranches. Some students have also worked for federal (i.e., national) and state agencies to fight wildfires or treat weed infested areas. The remaining students came from adjacent (Colorado, Montana, Idaho, and South Dakota) or more distant (Michigan, Wisconsin, Maryland, and Texas) states, with some or no background in farming and ranching.

\section{STUDENT RESEARCH PROJECTS}

As part of the course requirement, students are required to complete a term research project that takes approximately six weeks to complete. Projects have to focus on the applications of remotely sensed data to address natural resource or management issues. Often students select study areas that are familiar to them, such as family property, work sites, or public lands such as forests, and lakes and reservoirs.

\subsection{Pre No-cost Landsat Era}

Students had access to 400+ Landsat images and 1,800 ASTER images that were part of the WyomingView's data archive (Sivanpillai, 2008). The Landsat images were mostly concentrated in certain parts of the state with intermittent temporal coverage. This prevented students from undertaking projects that required images that were unavailable for specific years, seasons, or months. For example, a student might have found two or more scenes from the spring season within the data archive, for their area of interest but not those that were acquired in late summer or early autumn. Often students would find images that only partially covered their study area in a scene. The adjacent scene would also not be present in the state archive. Such limitations forced students to modify their original research objective to match the existing inventory in WyomingView's data archive.
Despite these limitations, several students found the images they needed and used them in their project (Sivanpillai, 2008). Most of these projects focused on mapping land cover or conditions on the ground using one to three Landsat images. Students utilized changes in the spectral reflectance values of healthy and stressed vegetation, clear and turbid water, vegetation in burnt and unburned areas, etc. and generated land cover maps. However, very few studies focused on using four or more Landsat images because of the temporal gaps or presence of clouds, snow and/or ice.

\subsection{No-cost Landsat Era I (2009 - 2017)}

Since the fall semester of 2011, students have been downloading as many Landsat images as they need for their projects. Images are useful as long as clouds and shadows are not over their study areas or the location is not covered by ice or snow. The number of projects that focused on tracking intraand inter-annual changes increased many fold, in comparison to change analyses using two or at most 3 images in the Pre Nocost Landsat era. Almost half of the projects conducted by the students in this remote sensing course now use four or more Landsat images (Figure 1).
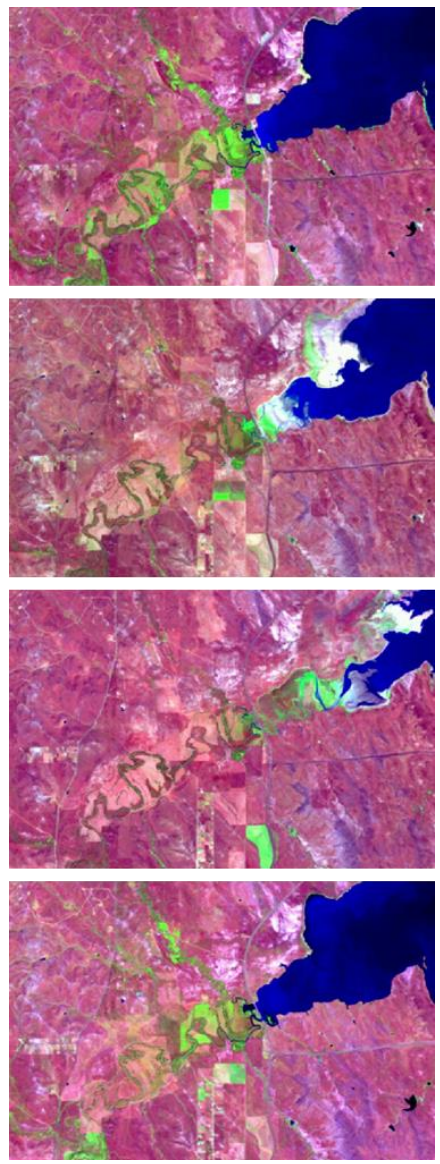

Figure 1. Landsat images acquired in 1999 (top), 2002, 2005, and 2011 (bottom) show vegetation growth or response in dry (2002 and 2005) and wet years (1999 and 2011) by Keyhole Reservoir near Moorcroft, Wyoming.

Landsat images are used for monitoring intra-annual changes in vegetation growth in Wyoming's rangelands, which are influenced by the amount of precipitation and other conditions. Landsat images acquired every 16 days captured changes at the start of the 2007 growing season (Figure 2). 

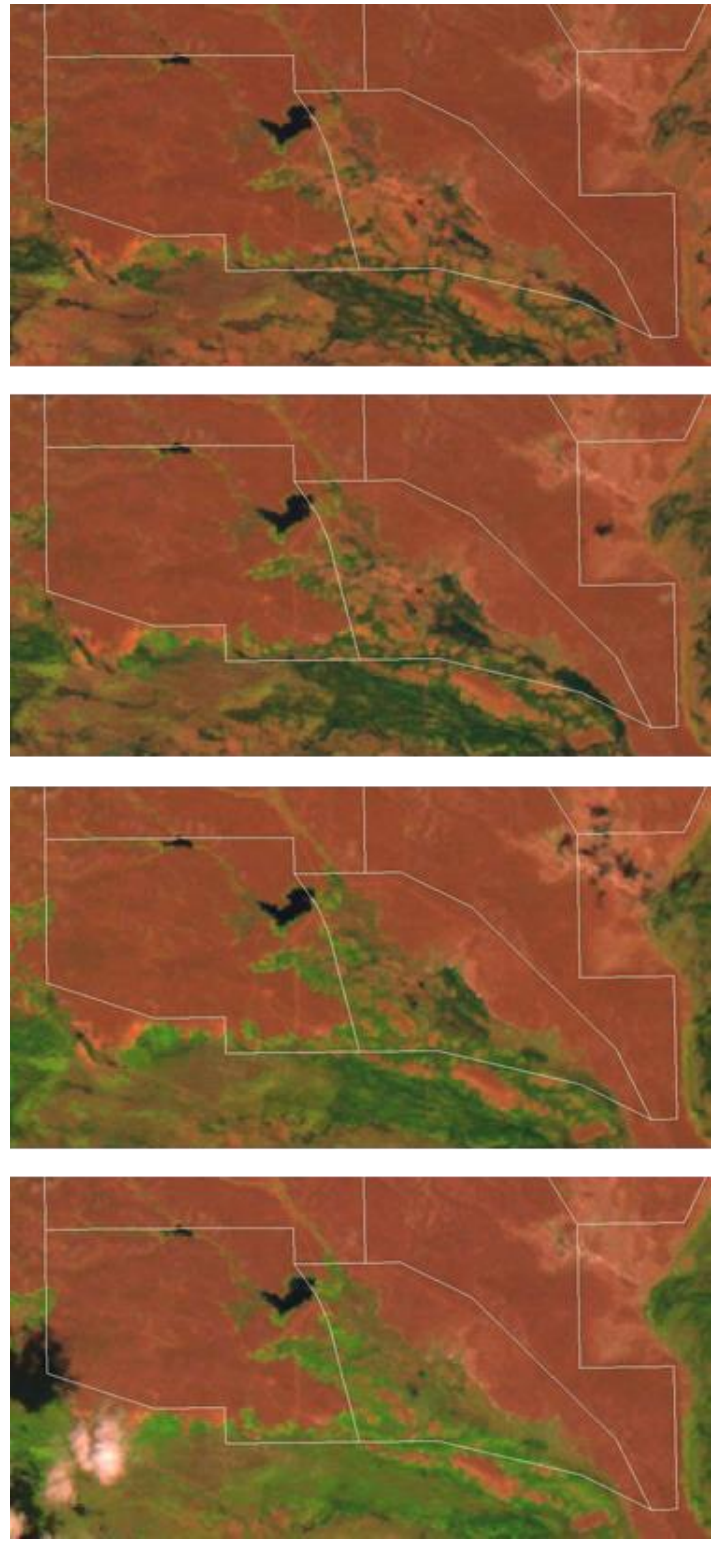

Figure 2. Landsat images acquired from May (top) through July (bottom) 2007 show both vegetation growth in allotments that had different management practices and water body surface area changes. Allotment boundaries (white in colour) were added to this image.

Students also capitalized on Landsat' long-term data record and have been mapping surface area changes for reservoirs in the state that are not gauged (Figure 3). Currently, there are no field records on the amount of water stored in these reservoirs. Students processed images acquired from 1984 and extracted their surface areas. Plotting these values and comparing them to precipitation data from nearby weather stations, students identified potential drivers of those changes.

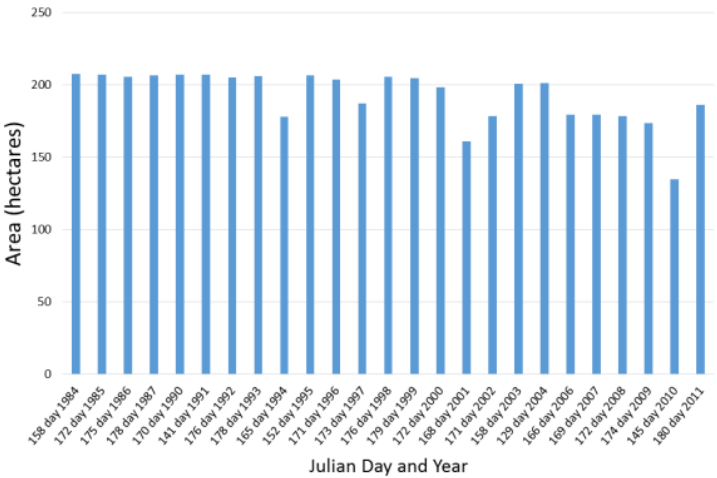

Figure 3. Surface area estimates for Ray Lake derived from Landsat 5 TM images acquired from 1984 through 2011 (Colleen Friday; Fall 2015).

However, prior to using multiple Landsat images in a single project, students have to check the associated metadata files for determining the positional accuracy of the image and make any necessary adjustments. This step requires spending extra time prior to extracting the information from the Landsat images.

\subsection{No-cost Landsat Era II (2017 - Present)}

In 2017 the USGS released the Landsat images in a Collection and Tier Level system/structure after reprocessing the entire archive (Micijevic et al., 2016). Images meeting the highest quality standards were placed in the first tier, and those that failed to meet those standards were placed in the second tier. Landsat images placed in the first tier are also suitable for pixelby-pixel level change analyses.

Students, and any users, can now quickly identify and download high quality Landsat scenes for their area of interest. The Collection Level product also eliminates the time needed to align the images prior to information extraction and allows instructors to bring the classroom discussion to a higher level. Students can now focus on any of the image processing steps they propose to use in their project.

In early 2020, the USGS plans to reprocess and release Collection Level 2. Users can download Landsat and the European Space Agency's Sentinel 2 data and increase the temporal resolution in their projects. The new collection will create additional opportunities for monitoring more sites in Wyoming that experience relatively more cloud cover.

\section{CONCLUSION}

Availability of no-cost Landsat data has crreated unprecedented opportunities for students to complete their term research projects. Students and instructors can access Tier 1 (highest quality) imagery data dating back to 1972 for conducting change analyses without having to realign the images. By working with images acquired for an area or region that is familiar to them, students develop a better and deeper understanding of remote sensing concepts introduced in lectures and laboratory exercises. Finally, products generated by students can provide valuable feedback to the USGS and other space agencies that are developing the next generation of remote sensing sensors. 


\section{ACKNOWLEDGEMENTS}

The author thanks Abigail Gettinger, University of Wyoming, for proof reading the earlier versions of this manuscript. This material is based upon work supported by the U.S. Geological Survey under Grant/Cooperative Agreement No. G18AP00077. The views and conclusions contained in this document are those of the author and should not be interpreted as representing the opinions or policies of the U.S. Geological Survey. Mention of trade names or commercial products does not constitute their endorsement by the U.S. Geological Survey. This manuscript is submitted for publication with the understanding that the United States Government is authorized to reproduce and distribute reprints for Governmental purposes.

\section{REFERENCES}

Arvor, D., Daher, F.R.G., Braind, D., Dufour, S., Rollet, A-J., Simones, M., Ferraz, R.P.D., 2018. Monitoring Thirty Years of Small Water Reservoirs Proliferation in the Southern Brazilian Amazon with Landsat time series. ISPRS Journal of Photogrammetry and Remote Sensing, 145: 225-237.

Hansen M.C., Potapov, P.V., Moore, R., Hancher, M., Turubanova, S.A, Tyukavina,, A, Thau, D., Stehman, S.V., Goetz, S.J., Loveland, T.R., Kommareddy, A., Egorov, A., Chini, L., Justice, C.O., Townshend, J.R.G., 2013. HighResolution Global Maps of 21st-Century Forest Cover Change, Science, 342(6160):850-853.

Hughes, M.J., Kaylor, S.D., Hayes, D.J., 2017. Patch-Based Forest Change Detection from Landsat Time Series. Forests 8(5), 166. DOI: $10.3390 / f 8050166$.

Landenberger, R., Patterson, M., Sivanpillai, R., Lawrence, R, 2011. AmericaView: Promoting Remote Sensing Science and Technology through Cooperative Partnerships. Photogrammetric Engineering and Remote Sensing 77(10), 969-974.

Lindsay, F. E., Townshend, J.R.G., Jaja, J., Humphries, J., Plaisant, C, Shneiderman, B., 1999. Developing the Next Generation of Earth Science Data Systems: the Global Land Cover Facility. IEEE 1999 International Geoscience and Remote Sensing Symposium. IGARSS'99 (Cat. No.99CH36293). DOI: 10.1109/IGARSS.1999.773583.

Loomis, J., Koontz, S., Miller, H., Richardson, L., 2015. Valuing geospatial information: Using the contingent valuation method to estimate the economic benefits of Landsat satellite imagery, Photogrammetric Engineering \& Remote Sensing, 81(8):647-656.

Micijevic, E., Haque, M.O., Mishra, N., 2016. Radiometric Calibration Updates to the Landsat collection. Volume 9972, Earth Observing Systems XXI; 99720D (2016). DOI: $10.1117 / 12.2239426$.

Rufin, P., Frantz, D., Ernst, S., Rabe, A., Griffithis, P., Ozdogan, M., Hostert, P., 2019. Mapping Cropping Practices on a National Scale Using Intra-Annual Landsat Time Series Binning. Remote Sensing, 11(3), 232. DOI: 10.3390/rs11030232.

Sivanpillai, R., 2008. Remote Sensing Education through Interactive Learning. Proceeding of the Pecora 17 - The
Future of Land Imaging ... Going Operational, Denver CO, USA.

Sivanpillai, R., Driese, K.L., 2008. Promoting Remote Sensing Education and Research through WyomingView data resources. Journal of Geography 107(4-5): 154-160.

Wulder, M.A., J.G. Masek, W.B. Cohen, T.R., Loveland, and C.E. Woodcock, 2012. Opening the Archive: How Dree Data has Enabled the Science and Monitoring Promise of Landsat, Remote Sensing of Environment, 122: 02-10.

Zhu, Z., 2017. Change Detection Using Landsat Time Series: A Review of Frequencies, Preprocessing, Algorithms, and Applications. International Journal of Photogrammetry and Remote Sensing, 130: 370-384. 